\title{
The Natural History of Brain Arteriovenous Malformations
}

\section{História natural das malformações arteriovenosas encefálicas}

\author{
Carlos Michel Albuquerque Peres ${ }^{1}$ Vitor Nagai Yamaki ${ }^{2}$ Eberval Gadelha Figueiredo ${ }^{2}$ \\ ${ }^{1}$ Department of Neurosurgery, Hospital Santa Julia, Manaus, \\ AM, Brazil \\ 2 Division of Neurosurgery, School of Medicine, Universidade de São \\ Paulo, São Paulo, SP, Brazil

\begin{abstract}
Address for correspondence Carlos Michel Albuquerque Peres, MD, Department of Neurosurgery, Hospital Santa Julia, Av. Jorn. Umberto Calderaro Filho, 455 / 1204, Manaus, AM 69057-015, Brazil
\end{abstract} \\ (e-mail: cmaperes@mac.com).
}

Arq Bras Neurocir 2017;36:153-159.

\begin{abstract}
Keywords

- intracranial arteriovenous malformations

- arteriovenous fistula

- cerebral hemorrhage

- natural history of diseases
\end{abstract}

\section{Resumo}

Brain arteriovenous malformations (AVMs) are relatively rare lesions with irreversible consequences in the context of hemorrhage. They are characterized by direct connections between arteries and veins without an intervening capillary network. The natural history of brain AVMs is controversial in the literature, with low evidence level gathered in the papers published, and with large divergence of results among them. A detailed understanding of the natural history is critical for treatment decision. The risk of development of deleterious outcomes such as hemorrhage or brain infarction should always be considered when submitting a patient to the risks of treatment. Several factors related to the patient and to the AVMs are determinants in the natural history of this disease. The topography, size, morphology and angioarchitecture of AVMs determine the risk of rupture. Large AVMs, those located in the posterior fossa and with deep venous drainage, have higher risk of rupture. Due to divergence in the literature regarding the natural history of AVMs, the choice of treatment should also consider experiences acquired over the years from reference centers with a high number of AVMs treated per year. We determined 7 variables that should be considered during the decision to treat an AVM: 1) previous hemorrhage; 2) aneurysm associated to the AVM; 3 ) direct arteriovenous fistula; 4) factors related to the nidus; 5) age and habits (smoking, sedentary lifestyle, diet quality); 6) the functional performance of the patient; 7) psychological factors.

Malformações arteriovenosas (MAVs) são lesões caracterizadas por conexões diretas entre artérias e veias sem rede capilar. São relativamente raras e com consequências muitas vezes irreversíveis no contexto de hemorragia. A história natural das MAVs é controversa na literatura, com pouca evidência extraída dos artigos publicados, além de alta divergência entre resultados. Um entendimento detalhado da história natural da doença é determinante para a decisão do tratamento. O risco de desenvolver received

May 18, 2017

accepted

June 5, 2017

published online

July 19, 2017
DOI https://doi.org/

10.1055/s-0037-1604344. ISSN 0103-5355.
Copyright $(2017$ by Thieme Revinter

Publicações Ltda, Rio de Janeiro, Brazil
License terms

(요 (1) $\Theta$ 
Palavras-chave

- malformações arteriovenosas intracranianas

- fístula arteriovenosa

- hemorragia cerebral

- história natural das doenças consequências deletérias como hemorragia ou isquemia deve ser sempre considerado antes de submeter pacientes ao tratamento. Vários fatores relacionados ao paciente e às MAVs são determinantes na história natural da doença. A localização, tamanho, morfologia e angioarquitetura das MAVs estimam o risco de ruptura. As MAVs grandes, de fossa posterior, com drenagem venosa profunda, têm maior risco de ruptura. A decisão de tratar deve também levar em conta a experiência do serviço, adquirida após anos de tratamento de MAVs. Nós determinamos 7 fatores que devem ser avaliados diante da decisão de tratamento das MAVs: 1) hemorragia prévia; 2) aneurismas associados à MAV; 3) fístula arteriovenosa; 4) fatores relacionados ao nidus; 5) idade e hábitos de vida; 6) performance funcional do paciente; 7) fatores psicológicos.

\section{Introduction}

Brain arteriovenous malformations (AVMs) are characterized by a nidus of abnormal vessels that forms a direct connection between arteries and veins, without an intervening capillary bed, resulting in one or several arteriovenous fistulas in the same lesion. ${ }^{1,2}$ Arteriovenous malformations have specific characteristics according to their topography, size, morphology, and angioarchitecture. Therefore, the choice of treatment should be individualized for each patient. Despite the relatively low prevalence ( 16 cases per 100,000 habitants), ${ }^{3}$ they are the most frequent etiology of non-traumatic intracranial hemorrhage in the young population $(<40$ years old). ${ }^{4,5}$

Although several papers have been published recently, there are no evidence-based guidelines for the treatment of AVMs. ${ }^{6}$ Most studies addressing the natural history of this disease were conducted with an observational design with low statistical power for consistent conclusions; in addition, there is a large disagreement among the results presented in the literature. Thus, the risk factors should be carefully taken into consideration before the decision to treat these lesions. ${ }^{7}$

\section{The Natural History of AVM}

There is a large spectrum of AVMs presenting symptom, such as:

- Cerebral hemorrhage (50\%): the neurological deficit is related to the topography of the lesion inside the parenchyma, or to its extension to the subarachnoid or ventricular compartments.

- Seizure (30\%): the seizure semiology might be related to specific locations in the brain, especially for focal seizures.

- Headache (14\%).

- Other symptoms: neurological deficit (related to inadequate blood influx caused by the AVM shunt); and pulsatile tinnitus.

The frequency of these symptoms varies according to the geographical differences of the population studied: hemorrhage represented $71 \%$ of AVM presenting symptoms in
Nordic countries, while in the United States and Europe the rates were $42 \%$ and $52 \%$ respectively. ${ }^{8,9}$

The most common hemorrhage caused by AVM rupture is intraparenchymal bleeding; but, in $24 \%$ of the cases, subarachnoid or ventricular hemorrhage may be associated. ${ }^{10,11}$ Arteriovenous malformations are usually isolated lesions, except when they are included in the manifestations of genetic diseases, such as hemorrhagic hereditary telangiectasia (Rendu-Osler-Weber disease). ${ }^{12}$

The first question to be answered is related to the decision of whether to treat AVMs: is the risk of hemorrhage higher than the risk of the treatment? Unfortunately, such details on the natural history of AVMs remain unknown. The first studies that came out addressing this issue were surgical case series with only frequency variables analyzed retrospectively. ${ }^{13,14}$ Nowadays, the multivariate analysis in large prospective series predicts the annual risk of rupture related to a specific risk factor. This study design is certainly adding more evidence to the literature over time. ${ }^{15}$

Intracranial hemorrhage was the most frequent symptom ( $65 \%$ of cases) at admission in a population study conducted by the Mayo Clinic in the state of Minnesota, USA. The incidence rate of the first hemorrhage was of 0.82 per 100.000 people/year; $75 \%$ of the bleeding events happened in patients under 50 years old, and the mortality rate in 30 days was of $17.5 \%{ }^{16}$

Ondra et al, ${ }^{11}$ in a prospective study of 166 symptomatic AVM patients with 24 years of follow-up, found an annual rate of rupture of $4 \%$ per year, and a mortality rate of $1 \%$ per year. At the end of this study, $23 \%$ of the patients had died of hemorrhage. This study was a landmark for the natural history of AVMs. However, the data included ruptured and unruptured AVMs in the same analysis; moreover, most patients had their hemorrhages detected clinically or by lumbar puncture, since the computerized tomography (CT) scan only became available after 1973 , while the study was accomplished in $1975 .{ }^{17}$

Considering the annual risk of rupture between $2-4 \%$ for unruptured AVMs, a formula to estimate the risk of hemorrhage has been suggested. ${ }^{8,18,19}$

RISK OF HEMORRHAGE $(\%)=105$-AGE 
This formula was created based on a homogeneous population, and does not consider additional risk factors that might increase the chances of hemorrhage, such as: associated aneurysms, venous drainage stenosis, and AVM topography.

In 2008, a Finnish study included 238 patients with untreated AVMs from admission to the beginning of treatment or hemorrhage or death. The study lasted from 1942 until 2005 , with a median follow-up of 13.5 years. The annual rate of hemorrhage was of $2.4 \%$, and the risk factors identified were: younger population, previous rupture, deep location, infratentorial lesions and those with exclusive deep venous drainage. ${ }^{20}$ Then, a Canadian study ${ }^{21}$ with 678 patients (211 previously submitted to partial embolization), using the same statistic tests, found an annual risk of hemorrhage of $4.6 \%$. Even though both studies were performed under same conditions and methodological requirements, the Canadian population presented a risk of hemorrhage $\sim 2$ times higher.

The study "Columbia and the New York Island" (Columbia AVM Database project and the New York Islands AVM study) 22,23 performed a prospective analysis of over 600 patients. The main findings of this study were:

- Annual incidence of hemorrhage of $34.4 \%$ for patients with 3 simultaneous risk factors: previous hemorrhage, deep location and deep venous drainage.

- Annual incidence of hemorrhage determined at $4.5 \%$ for patients with only previous hemorrhage.

- For patients without previous hemorrhage, the annual rate of hemorrhage was 3.1\% for deep location AVMs; $2.4 \%$ for AVMs with deep venous drainage; and $0.9 \%$ for patients without any risk factor. ${ }^{17}$

The study called "A Randomized Trial of Unruptured Brain Arteriovenous Malformations" (ARUBA) gathered results from different institutions worldwide, and found that the conservative treatment had better outcomes than intervention (surgery, radiosurgery, embolization). However, this study recruited only 226 out of the initially planned sample of 400 patients due to a National Institution of Health (NIH) safety board intervention, since the preliminary results showed symptomatic stroke or death in $10 \%$ of the patients for the clinical treatment group, and in $31 \%$ of those submitted to any intervention $(p<0.0001)$ during a mean followup of 33 months. $^{24}$

The external validity of the ARUBA trial was questioned since AVMs with different grades were analyzed together, as well as different interventions (surgery, coiling, radiosurgery). There was a considerable selection bias in the recruitment of the patients. Several centers in the United States did not contribute with the research due to lack of clinical equipoise, since there was not enough doubt to justify the randomization instead of treating patients with high risk factor unruptured AVMs. ${ }^{25}$-Table 1 summarizes the main shortcomings of the ARUBA trial.

In a meta-analysis published by the American Association of Neurological Surgeons, ${ }^{13}$ Gross and Du gathered information from 9 natural history studies with 3.923 patients and 18.423 patient-years of follow-up. The annual rate of hemorrhage was of $2.2 \%$ (95\% confidence interval [95\%CI]: $1.7-$ 2.7\%) for unruptured AVMs; and of 4.5\% (95\%CI: 3.7-5.5\%) for ruptured AVMs. These results might be influenced by the risk factors that will be described in the next section.

\section{Risk Factors for AVM hemorrhage}

Arteriovenous malformations belong to a heterogeneous group of cerebrovascular diseases in which several risk factors influence the risk of rupture. A well-designed multivariate analysis can differentiate the independent risk factors from those that are just associated with a positive predictive value. ${ }^{9}$ For example, it was postulated that AVMs with a small nidus have higher risk of rupture. However, a prospective Finnish study proved that a larger nidus is a good predictor of future hemorrhagic events. ${ }^{26,27}$ Another relationship previously accepted was that younger patients were more prone to AVM rupture; however, the opposite relation showed statistical significance in the most current

Table 1 ARUBA trial shortcomings

\begin{tabular}{|l|l|}
\hline Topic & Limitations \\
\hline Study design & $\begin{array}{l}\text { Absence of therapeutic plan: selection bias (the European centers randomized more for endovascular } \\
\text { therapy, while the American centers randomized more AVMs for the surgery group). }\end{array}$ \\
\cline { 2 - 3 } & $\begin{array}{l}\text { The study did not analyze the outcomes with different interventions separately. Thus, the study } \\
\text { suggested the superiority of the clinical treatment for all kinds of unruptured AVMs, but failed to } \\
\text { determine whether this is true for one specific treatment modality. }\end{array}$ \\
\cline { 2 - 3 } & $\begin{array}{l}\text { The study did not evaluate the associated conditions that would increase the risk of AVM rupture, } \\
\text { such as: the angioarchitecture and topography of the lesions, and the presence of aneurysms. } \\
\text { Therefore, the study failed to conclude if the clinical treatment is superior for all types of AVMs. }\end{array}$ \\
\cline { 2 - 3 } & $\begin{array}{l}\text { The requirement for participation in the study was } 10 \text { AVMs treated per year. This may suggest that } \\
\text { centers unexperienced in AVMs collaborated with the treatment outcomes. }\end{array}$ \\
\hline Study conduction & Short follow-up (3 years); intervention group still under analysis. \\
\cline { 2 - 2 } & Cohort shorter than planned (interrupted for ethical and safety issues). \\
\hline
\end{tabular}

Abbreviations: ARUBA, A Randomized Trial of Unruptured Brain Arteriovenous Malformations; AVMs, arteriovenous malformations. 
large series. ${ }^{28}$ It is noteworthy that the most updated knowledge about AVMs is based on non-randomized observational studies with some degree of methodological bias. ${ }^{7}$

-Fig. 1 depicts a case of hemorrhagic brain AVM showing an unusual evolution in adults, but relatively well-described in children. A 7-year-old male child presented an intraventricular hemorrhage in 2004 (-Fig. 1A). The patient was treated with embolization, follow-up magnetic resonance imaging (MRI) exams, and two digital subtraction angiographies (DSAs). The last DSA, in 2009, showed radioanatomical cure (data not shown). In 2014 (10 years after the bleeding), the patient developed seizures. Magnetic resonance imaging (-Fig. 1B) and DSA (-Fig. 1C) showed the AVM in the medial left occipital lobe. The patient underwent total microsurgical resection of the lesion ( - Fig. 1D), without new deficits.
The evidence-based variables related to the risk of rupture in the literature are: ${ }^{13,29}$

- Previous hemorrhage: hazard ratio (HR): 5.38 (95\% $\mathrm{CI}$ : 2.64-10.96), and annual rate of rupture: $9.56-15.42 \%{ }^{9,17,23}$

- Deep location of AVMs: HR: 3.25 (95\%CI: 1.30-8.16); ${ }^{23}$ thalamic, basal nuclei, and brainstem AVMs have hemorrhage as the presenting symptom in $72-91 \%$ of cases, ${ }^{23,30}$ although they represent only $5-10 \%$ of AVMs

- Exclusive deep venous drainage: HR: 3.25 (95\%CI: 1.01$5.67) ;{ }^{23}$ here there is a confounding factor because these lesions often coincide with deeply-located lesions. More studies are necessary to determine deep venous drainage as an independent risk factor for the rupture of AVMs. The annual risk of hemorrhage for deep venous drainage and deep location AVMs is of $8 \%$; however, when combining

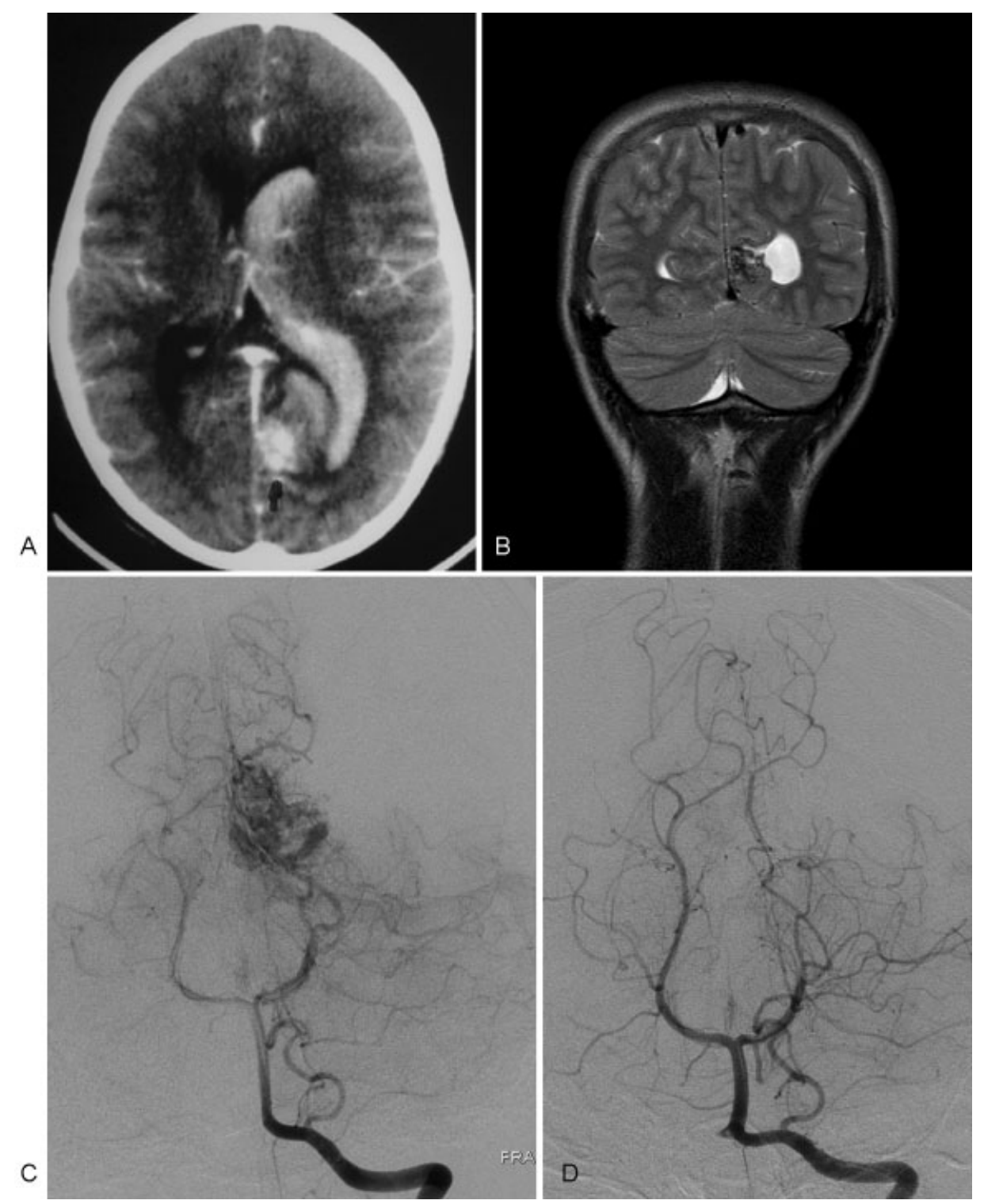

Fig. 1 (A) Computed tomography (CT) scan shows a hemorrhagic occipital arteriovenous malformation (AVM). (B) Coronal magnetic resonance imaging (MRI) showing a medial paraventricular occipital AVM. (C) Digital subtraction angiography (DSA) after 10 years of the initial hemorrhage. (D) Post-microsurgical AVM resection DSA. 
deep venous drainage with previous bleeding, the risk is of $11.4 \%$ per year. ${ }^{9,27}$

- Arteriovenous fistula: it is characterized by direct connections between arteries and veins without a nidal network interposed. Those fistulas might be within the $\mathrm{AVM}^{31}$ nidus, which may be identified only through super selective DSA with microcathethers. ${ }^{31}$

- Venous ectasias: they are characteristic of reduced venous drainage, which is considered a risk factor for rupture. The hemorrhage happens by rupture of the nidal vessels, often the vein of drainage, for increased pressure or thrombosis. ${ }^{32}$

- AVM-related aneurysms: aneurysms are present in 2.3\% to $16.7 \%$ of brain AVMs. ${ }^{33}$ They represent a risk factor for hemorrhage, with an odds ratio of 1.8 (95\% CI: $1.6-2.0) .^{13}$ Aneurysms on the distal arterial branches (closer to the nidus) or intranidal aneurysms are more prone to rupture. It is a hard task to identify intranidal aneurysms, for their identification depends on a good-quality microcathetherization. ${ }^{34}$ Some authors consider those aneurysms originating from the venous system, since, histologically, the nidus is more related to the venous structure. ${ }^{34,35}$ Proximal aneurysms (Willis polygon arteries), related or not to the arterial influx of the nidus, do not increase the risk of AVM hemorrhage. Some authors advocate that they should be treated as saccular aneurysms, according to the findings of the International Study of Unruptured Intracranial Aneurysms (ISUIA). ${ }^{34,36,37}$ Proximal aneurysms are more easily diagnosed by DSA, and have a higher incidence in the elderly and posterior circulation. ${ }^{38}$

\section{Treatment indications for Arteriovenous Malformation}

The decision of whether to treat an AVM or not is not a simple task, especially for the unruptured lesions. A strict clinical pre-operative evaluation is mandatory, including age, detailed neurological examination, use of anti-epileptic drugs, perspectives about the disease, degree of disability, and its influence in daily life activities. The modified Rankin scale is the most relevant scale to stratify these patients. - Fig. 2 shows the case of a valid option for conservative treatment. A 42 year-old woman, a Portuguese language college professor, with a single episode of seizure, which was well-controlled with anticonvulsant monotherapy. Conservative treatment was chosen. This is the 4 th year MRI ( - Fig. 2A) and second digital subtraction angiography (-Fig. 2B), unchanged related to the first one (data not shown).

In addition, a detailed neuroimaging evaluation should be performed, including an MRI with susceptibility weighted imaging, and good-quality DSA with at least 4 frames per second. Three-dimensional imaging reconstructions and microcatheterization techniques will provide additional information on the therapeutic plan, as well as enhance the possibility of detecting small intranidal aneurysms.

The classification of AVMs as ruptured and unruptured is based on clinical presentation and imaging findings (CT or MRI). They can also be differentiated according to histological characteristics after microsurgical resection. The unruptured AVMs, in more than $30 \%$ of cases, show microhemorrhages due to the presence of hemosiderin and macrophages. ${ }^{38}$

Magnetic resonance imaging sequencing with increased iron sensibility, such as $\mathrm{T} 2{ }^{*}$ gradient echo and susceptibilityweighted images, might detect microhemorrhages in asymptomatic AVM patients. The micro hemorrhage found in those patients can be compared with sentinel hemorrhage in the aneurismal subarachnoid hemorrhage. ${ }^{39,40}$

Before making the decision to treat or not an AVM, it is always important to consider:

1. Previous hemorrhage.

2. Aneurysm associated to the AVM.
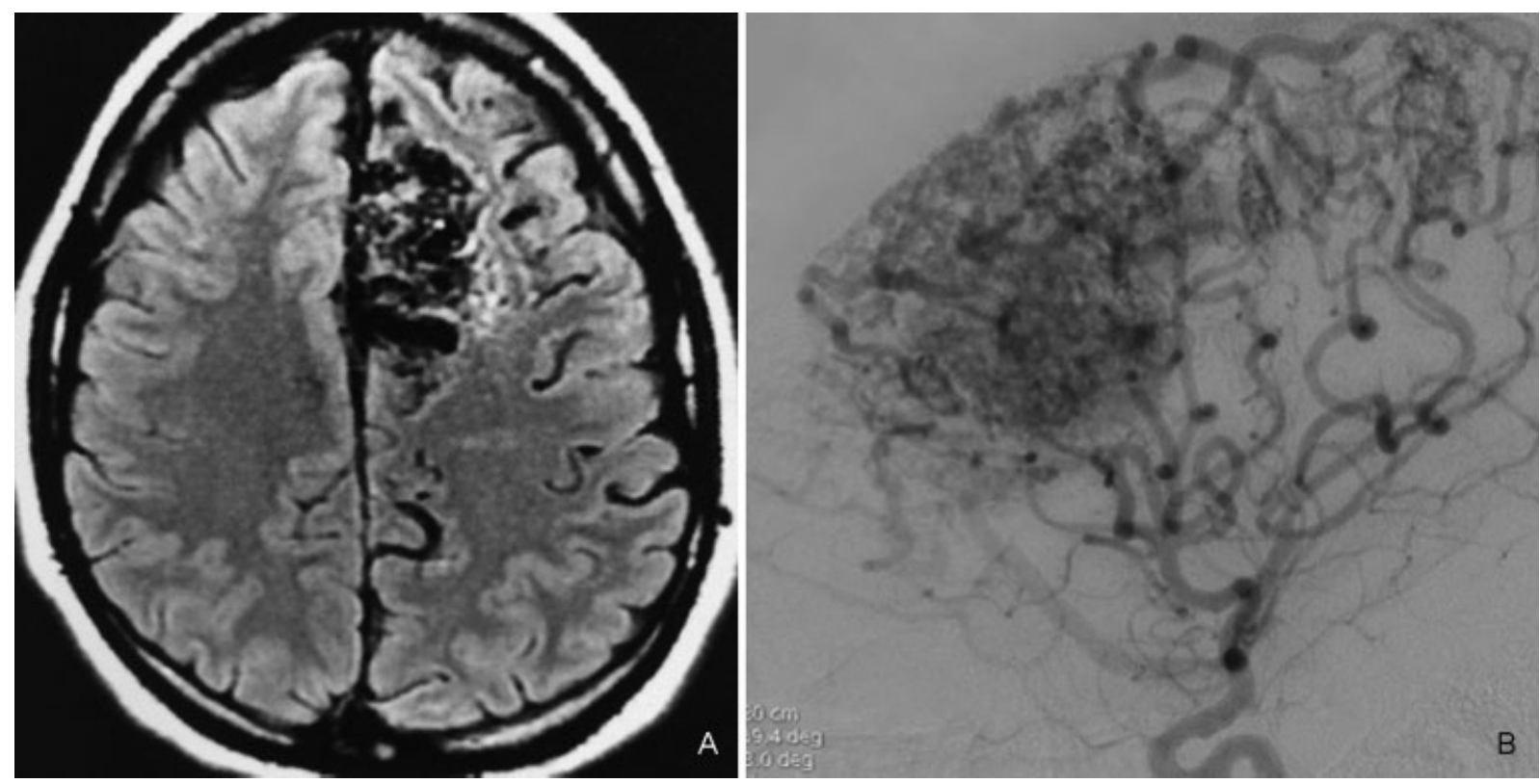

Fig. 2 (A) MRI showing a left frontal unruptured AVM. (B) DSA showing a left frontal unruptured AVM. 
Table 2 AVM annual bleeding rate according to previous hemorrhage, venous drainage pattern and nidus topography 9,17

\begin{tabular}{|l|l|l|l|}
\hline Previous hemorrhage & Superficial venous drainage & Deep venous drainage & Nidus topography \\
\hline \multirow{2}{*}{ Unruptured AVM } & $0.9 \%$ & $2.4 \%$ & Superficial nidus \\
\cline { 2 - 4 } & $3.1 \%$ & $8.0 \%$ & Deep nidus \\
\hline \multirow{2}{*}{ Ruptured AVM } & $14.8 \%$ & $34.4 \%$ & \\
\cline { 2 - 4 } & $4.5 \%$ & $11.4 \%$ & Superficial nidus \\
\hline
\end{tabular}

Abbreviation: AVM, arteriovenous malformation.

3. Direct arteriovenous fistula.

4. Factors related to the nidus.

5. Age and habits (smoking, sedentary lifestyle, diet quality).

6. The functional performance of the patient.

7. Psychological factors.

The aforementioned topics do not represent a consensus in the literature. However, there is no guideline with level 1 or 2 of evidence addressing the treatment decisions in AVMs. Therefore, the decisions should be taken based on the evidences that fit better according to the clinical practice experience; moreover, a multidisciplinary discussion (with neuroradiologists, neurologists, neurosurgeons, and radiotherapists) is mandatory in order to achieve better outcomes. Since it is a relatively rare disease, favorable outcomes might be easily reached through specialized AVM centers with enough cases and acquired experience over time. - Table 2 summarizes the annual rate of AVM rupture according to topographic and vascular variables.

\section{References}

1 McCormick WF. The pathology of vascular ("arteriovenous") malformations. J Neurosurg 1966;24(04):807-816

2 Atkinson RP, Awad IA, Batjer HH, et al; Joint Writing Group of the Technology Assessment Committee American Society of Interventional and Therapeutic Neuroradiology; Joint Section on Cerebrovascular Neurosurgery a Section of the American Association of Neurological Surgeons and Congress of Neurological Surgeons; Section of Stroke and the Section of Interventional Neurology of the American Academy of Neurology. Reporting terminology for brain arteriovenous malformation clinical and radiographic features for use in clinical trials. Stroke 2001;32(06): 1430-1442

3 Al-Shahi R, Fang JS, Lewis SC, Warlow CP. Prevalence of adults with brain arteriovenous malformations: a community based study in Scotland using capture-recapture analysis. J Neurol Neurosurg Psychiatry 2002;73(05):547-551

4 Fleetwood IG, Steinberg GK. Arteriovenous malformations. Lancet 2002;359(9309):863-873

5 Ruíz-Sandoval JL, Cantú C, Barinagarrementeria F. Intracerebral hemorrhage in young people: analysis of risk factors, location, causes, and prognosis. Stroke 1999;30(03):537-541

6 Pollock BE. The alchemy of brain arteriovenous malformation management. World Neurosurg 2015;83(03):337-338

7 Raymond J, Naggara O, Guilbert F, Altman DG. Assessing prognosis from nonrandomized studies: an example from brain arteriovenous malformations. AJNR Am J Neuroradiol 2011;32(05): 809-812
8 Ogilvy CS, Stieg PE, Awad I, et al; Stroke Council, American Stroke Association. Recommendations for the management of intracranial arteriovenous malformations: a statement for healthcare professionals from a special writing group of the Stroke Council, American Stroke Association. Circulation 2001; 103(21):2644-2657

9 Abecassis IJ, Xu DS, Batjer HH, Bendok BR. Natural history of brain arteriovenous malformations: a systematic review. Neurosurg Focus 2014;37(03):E7

10 Graf CJ, Perret GE, Torner JC. Bleeding from cerebral arteriovenous malformations as part of their natural history. J Neurosurg 1983; 58(03):331-337

11 Ondra SL, Troupp H, George ED, Schwab K. The natural history of symptomatic arteriovenous malformations of the brain: a 24-year follow-up assessment. J Neurosurg 1990;73(03):387-391

12 Brown RD Jr, Flemming KD, Meyer FB, Cloft HJ, Pollock BE, Link ML. Natural history, evaluation, and management of intracranial vascular malformations. Mayo Clin Proc 2005;80(02):269-281

13 Gross BA, Du R. Natural history of cerebral arteriovenous malformations: a meta-analysis. J Neurosurg 2013;118(02):437-443

14 Forster DM, Steiner L, Håkanson S. Arteriovenous malformations of the brain. A long-term clinical study. J Neurosurg 1972;37(05): 562-570

15 Stefani MA, Porter PJ, terBrugge KG, Montanera W, Willinsky RA, Wallace MC. Angioarchitectural factors present in brain arteriovenous malformations associated with hemorrhagic presentation. Stroke 2002;33(04):920-924

16 Brown RD Jr, Wiebers DO, Torner JC, O'Fallon WM. Frequency of intracranial hemorrhage as a presenting symptom and subtype analysis: a population-based study of intracranial vascular malformations in Olmsted Country, Minnesota. J Neurosurg 1996;85 (01):29-32

17 Stapf C, Mohr JP, Choi JH, Hartmann A, Mast H. Invasive treatment of unruptured brain arteriovenous malformations is experimental therapy. Curr Opin Neurol 2006;19(01):63-68

18 Kondziolka D, McLaughlin MR, Kestle JR. Simple risk predictions for arteriovenous malformation hemorrhage. Neurosurgery 1995;37(05):851-855

19 Brown RD Jr. Simple risk predictions for arteriovenous malformation hemorrhage. Neurosurgery 2000;46(04):1024

20 Hernesniemi JA, Dashti R, Juvela S, Väärt K, Niemelä M, Laakso A. Natural history of brain arteriovenous malformations: a longterm follow-up study of risk of hemorrhage in 238 patients. Neurosurgery 2008;63(05):823-829, discussion 829-831

21 da Costa L, Wallace MC, Ter Brugge KG, O'Kelly C, Willinsky RA, Tymianski $M$. The natural history and predictive features of hemorrhage from brain arteriovenous malformations. Stroke 2009;40(01):100-105

22 Stapf C, Mast H, Sciacca RR, et al; New York Islands AVM Study Collaborators. The New York Islands AVM Study: design, study progress, and initial results. Stroke 2003;34(05):e29-e33

23 Stapf C, Mast H, Sciacca RR, et al. Predictors of hemorrhage in patients with untreated brain arteriovenous malformation. Neurology 2006;66(09):1350-1355 
24 Mohr JP, Parides MK, Stapf C, et al; international ARUBA investigators. Medical management with or without interventional therapy for unruptured brain arteriovenous malformations (ARUBA): a multicentre, non-blinded, randomised trial. Lancet 2014; 383(9917):614-621

25 Amin-Hanjani S. ARUBA results are not applicable to all patients with arteriovenous malformation. Stroke 2014;45(05):1539-1540

26 Spetzler RF, Hargraves RW, McCormick PW, Zabramski JM, Flom RA, Zimmerman RS. Relationship of perfusion pressure and size to risk of hemorrhage from arteriovenous malformations. J Neurosurg 1992;76(06):918-923

27 Laakso A, Hernesniemi J. Arteriovenous malformations: epidemiology and clinical presentation. Neurosurg Clin N Am 2012;23 (01):1-6

28 Fullerton HJ, Achrol AS, Johnston SC, et al; UCSF BAVM Study Project. Long-term hemorrhage risk in children versus adults with brain arteriovenous malformations. Stroke 2005;36(10):2099-2104

29 Pollock BE, Flickinger JC, Lunsford LD, Bissonette DJ, Kondziolka D. Factors that predict the bleeding risk of cerebral arteriovenous malformations. Stroke 1996;27(01):1-6

30 Cheng C-H, Crowley RW, Yen C-P, Schlesinger D, Shaffrey ME, Sheehan JP. Gamma Knife surgery for basal ganglia and thalamic arteriovenous malformations. J Neurosurg 2012;116(04):899-908

31 Yuki I, Kim RH, Duckwiler G, et al. Treatment of brain arteriovenous malformations with high-flow arteriovenous fistulas: risk and complications associated with endovascular embolization in multimodality treatment. Clinical article. J Neurosurg 2010;113 (04):715-722

32 Valavanis A, Pangalu A, Tanaka M. Endovascular treatment of cerebral arteriovenous malformations with emphasis on the curative role of embolisation. Interv Neuroradiol 2005;11(01, Suppl 1):37-43
33 Miyasaka K, Wolpert SM, Prager RJ. The association of cerebral aneurysms, infundibula, and intracranial arteriovenous malformations. Stroke 1982;13(02):196-203

34 D'Aliberti G, Talamonti G, Cenzato M, et al. Arterial and venous aneurysms associated with arteriovenous malformations. World Neurosurg 2015;83(02):188-196

35 Cagnazzo F, Brinjikji W, Lanzino G. Arterial aneurysms associated with arteriovenous malformations of the brain: classification, incidence, risk of hemorrhage, and treatment-a systematic review. Acta Neurochir (Wien) 2016;158(11):2095-2104

36 Wiebers DO, Whisnant JP, Huston J III, et al; International Study of Unruptured Intracranial Aneurysms Investigators. Unruptured intracranial aneurysms: natural history, clinical outcome, and risks of surgical and endovascular treatment. Lancet 2003;362 (9378):103-110

37 Mansmann U, Meisel J, Brock M, Rodesch G, Alvarez H, Lasjaunias P. Factors associated with intracranial hemorrhage in cases of cerebral arteriovenous malformation. Neurosurgery 2000;46 (02):272-279, discussion 279-281

38 Morgan MK, Alsahli K, Wiedmann M, Assaad NN, Heller GZ. Factors Associated With Proximal Intracranial Aneurysms to Brain Arteriovenous Malformations: A Prospective Cohort Study. Neurosurgery 2016;78(06):787-792

39 Abla AA, Nelson J, Kim H, Hess CP, Tihan T, Lawton MT. Silent arteriovenous malformation hemorrhage and the recognition of "unruptured" arteriovenous malformation patients who benefit from surgical intervention. Neurosurgery 2015;76(05):592-600, discussion 600 discussion

40 Lawton MT, Abla AA. In Reply: Silent Arteriovenous Malformation Hemorrhage and the Recognition of "Unruptured" Arteriovenous Malformation Patients Who Benefit From Surgical Intervention. Neurosurgery 2015;77(05):E843-E844 